\title{
THE ELASTICITY OF HEALTH EXPENDITURE ON AGRICULTURAL PRODUCTIVITY GROWTH IN SOUTHEAST ASIA
}

\author{
Muhammad Muazu Bala', Shailender Singh2, Hawati Janor ${ }^{3}$ \\ 1. Department of Economics, School of Liberal Arts and Basic Sciences, SRM University-AP, Amaravati, India \\ 2. School of Entrepreneurship and Management Studies, SRM University-AP, Amaravati, India \\ 3. Faculty of Economics and Management, Universiti Kebangsaan Malaysia
}

Correspondence: reshul11us@yahoo.com

\section{ABSTRACT}

\section{BACKGROUND:}

Recently, agricultural productivity growth has experienced a sharp downward turn across the countries of Southeast Asia partly due to population ageing, increasing pace of urbanization, and industrialization.

\section{OBJECTIVE:}

To provide empirical evidence to the elasticity of prevailing health spending as a proxy of human capital stock on agricultural productivity growth in Southeast Asia.

\section{METHODS:}

This study analysed the data obtained from the World Development Indicators for 2000-2016 using panel data regression models.

\section{RESULTS:}

The empirical evidence suggests that prevailing health expenditure, though statistically significant, exerts a strong positive effect on agricultural productivity growth. Therefore, a unit rise in prevailing health spending relative to GDP would increase agricultural productivity growth by $28 \%$ across countries of Southeast Asia, all else constant.

\section{CONCLUSION:}

The trend of rapid agricultural productivity declines in Southeast Asia could be altered by augmenting investment to the prevailing health spending as an indicator of human capital stock.

\section{POLICY IMPLICATIONS:}

The governments of Southeast Asia should increase investment in prevailing health spending relative to GDP, to stimulate more growth in agricultural productivity, greatly improved human capital stock, and eventually increase economic growth

\section{KEYWORDS}

Health expenditure, productivity growth, human capital, Southeast Asia, SDGs. 


\section{INTRODUCTION}

The Sustainable Development Goals (SDGs) 3 emphasized on promoting good health and well beings for all people across age groups globally by the year 2030. [1] However, it has been understood that all the other 16 SDGs are centrally related to health and thus achieving the health target indirectly implied attaining the overall ambitious contemporary development targets, pertinent to all economies and regions of the world. The health target of SDGs accentuates the relevance of human capital as a catalyst to propelling economic development as argued by the endogenous growth models. [2] Accordingly, health is seen as an indispensable determinant of economic growth and development; higher productivity levels could be derived from a healthier population, and thus higher income per capita in the country. [3] The importance of health spending on economic growth and overall betterment of the well-being of population stems from the health-led growth hypothesis. [4] The hypothesis regards health as a crucial asset; and therefore, increasing total health spending in the economy would boost labor productivity, raise income per capita, and overall lead to improvement in the population living standards.

In many developing countries, agricultural productivity growth has accounted for the substantial share of GDP and in many instances, it's the mainstay of their economies. Thus, the comprehensive share of agricultural productivity growth relative to GDP has been declining over the years due to population ageing, the growing pace of industrialization, and urbanization in many contexts. Yet, the contribution of agriculture to the economic growth and development of many low and middle-income countries can never be overemphasized. Improving agricultural productivity remains a key priority in promoting sustainable development for developing countries. Liu and colleagues have highlighted that the growth of agricultural productivity in Southeast Asia has experienced a sharp downward turn, posing serious threats to sustainable agricultural growth in the region. [5] Hitherto, there have not been enough studies on the rapid declines in agricultural productivity growth in the region in relation to human capital stock which depreciates with age and time. Therefore, greater investment is needed for improving human capital stock and in turn productivity improvement over time.
The aim of the current study is to estimate the elasticity of prevailing health care expenditure relative to GDP on agricultural productivity growth measured in value-added per worker across the countries of Southeast Asia. However, this study contributes to the literature by providing empirical evidence to the concerned authorities of Southeast Asia on how to revamp the declining trend in agricultural productivity growth measured in value-added per worker through augmenting human capital investment and its farreaching positive economic externalities.

\section{LITERATURE}

The relationship between human capital stock, partly proxy as total health spending, and overall economic performance or economic growth has been established in the literature of economics over the years. For instance, in Pakistan, Ullah and colleagues have used the ARDL model and documented that an improvement in health status by 1 percent would result in $13.39 \%$ increase in the productivity of workers, among other factors that affect overall productivity levels considered in the model. [6] Golkhandan uses Granger Causality Test coupled with other statistical tests and established a statistically significant causal link between macroeconomic health indicators and the level of labour productivity in Iran. [7] Wang and colleagues have estimated the optimal health expenditure in a developing economy using GMM for the OECD countries over a period of one decade. Their empirical evidence shows that an increase in health spending, all else held constant, stimulates greater economic growth given that the share of health expenditure relative to GDP is below the optimum amount of $7.55 \%$. [8] Raghuphathi and colleagues have explored the association of health spending and economic performance in the US during the time of 2003-2014. They found that health care expenditure has a strong positive correlation with overall economic performance and labor productivity. [9]

Similarly, Bloom and colleagues have constructed a panel model of countries for over three decades and estimated the impact of the level of human capital on aggregate economic productivity using a production function model. They found that the state of the health of the population has a positive strong, albeit statistically significant impact on overall economic performance, assuming that workforce experience is held constant. [10] Ozturk and 
colleagues have used the panel ECM model and analyse the association of the level of health spending and economic productivity of G8 countries, spanning 1995 to 2012. Their findings suggest the presence of growth hypothesis and growth detriment hypothesis in the short run and long run respectively. [11] Piabuo and colleagues have studied health spending relations with economic growth between central African countries in comparison with other five African countries using panel OLS. Their empirical evidence shows that health expenditure has a statistically significant positive impact on growth during the study period. [12] Oni and colleagues have examined the relations of health expenditure on growth and their degree of causality. Their result indicates that total health spending, among other macro indicators, is statistically significant in promoting economic growth in Nigeria. [13]

Moreover, Arora investigates the impact of health on the patterns of the economic performance of ten industrialised economies over the span of a hundred to a hundred and twenty-five years. He documents that improvement in the stock of population health leads to an increase in their rate of growth by 30 to 40 percent, causing permanent change to their growth paths.[14] Brempong and colleague's comparative study used an expanded Solow growth model to examine the relations of the stock of human capital on per capita income growth rate between SubSaharan Africa and the OECD countries. Their findings highlight that the rate of per capita income growth is influenced positively by the share of human capital investment. [15] Aghion and colleagues have used panel data for the period of 1960-2000 and estimated the impact of health spending economic productivity in the light of the endogenous growth model. They concluded that improvement in the health of the population, though statistically significant has a positive correlation with per capita GDP growth in OECD countries. [16] Bedir studies the impact of health spending on the economic performance of developing economies using a modified version of the Granger causality test over the period of 1995-2013. Their empirical result shows that the income level of a country is a crucial factor in explaining the cross-country's variation in health expenditure. [17] Feng and colleagues have analysed the impact of public health spending on the productivity of labour in China, using panel data during 2007-2013. They have documented that public health expenditure is central to agricultural labour productivity betterment and also statistically significant in promoting even non-agricultural labour productivity. [18]
This is the first-panel study that investigates the elasticity of prevailing health spending relative to GDP on agricultural productivity growth measured in value-added per worker across the countries of Southeast Asia. The study has the following structure. Section two reviews the literature. Section three details the methodology and section four presents the empirical results. Finally, section five concludes the study.

\section{MATERIAL AND METHODS}

This study uses data obtained from the World Bank Development Indicators to examine the elasticity of prevailing health expenditure relative to GDP on agricultural productivity growth measured in value-added per worker across the countries of Southeast Asia for 2000 2016 periods. The period of the study was chosen by making optimum use of the available data. The baseline model seeks to investigate whether health spending relative to GDP has a statistically significant effect on agricultural productivity per worker. The model is given in logarithmic form as:

$$
\ln A P G_{i t}=\alpha_{i}+\beta \ln (P H E)_{i t}+\varepsilon_{i t}
$$

where $\ln A P G_{i t}$ indicates agricultural productivity growth and $\ln (P H E)$ represents the share of prevailing health expenditure relative to GDP across countries of Southeast Asia. The $i$ accounts for the cross-sectional differences for both health expenditure and agricultural productivity growth per worker across the countries for the period (t) 2000 to 2016, $\alpha_{i}$ is a constant and $\varepsilon_{i t}$ indicates the error term.

\section{RESULTS}

This section begins with analysing the trends in prevailing health expenditure and agricultural productivity growth in Southeast Asia followed by the identification of the right model for estimating the results.

Table 1 presents the pattern of both prevailing health expenditure and agricultural productivity growth measures in terms of value-added per worker. The trend shows a declining pattern of $-0.2 \%,-0.46 \%$, and $-1.92 \%$ in Brunei, Cambodia, and Laos respectively. Whereas, in other countries included in the study, the pattern of health expenditure exhibits a positive trend during the span of 
sixteen years. Concurrently, the volume of agricultural productivity per worker grew substantially among nine out of the ten countries of Southeast Asia. However, it was only in Singapore that the volume of agricultural productivity growth per worker has exhibited a cumulative decline of 296.531 units. This exceptional case of Singapore may not be surprising because it is the only developed country among the Southeast Asian block.

TABLE 1: TRENDS IN PREVAILING HEALTH SPENDING RELATIVE TO GDP AND AGRICULTURAL PRODUCTIVITY GROWTH IN SOUTHEAST ASIA (2000-2016)

\begin{tabular}{|l|l|l|l|l|l|l|}
\hline COUNTRY & PHE $_{2000}$ & PHE $_{2016}$ & CHANGE & APG $_{2000}$ & APG $_{2016}$ & CHANGE \\
\hline Brunei & 2.54 & 2.34 & --0.2 & 44061.65 & 58437.38 & 14375.73 \\
\hline Cambodia & 6.54 & 6.08 & -0.46 & 577.5902 & 1570.317 & 992.7268 \\
\hline Indonesia & 1.92 & 3.12 & 1.2 & 1785.04 & 3464.768 & 1679.728 \\
\hline Laos & 4.28 & 2.36 & -1.92 & 584.9252 & 777.1161 & 192.1909 \\
\hline Malaysia & 2.56 & 3.80 & 1.24 & 11353.23 & 17303.64 & 5950.41 \\
\hline Myanmar & 1.84 & 5.09 & 3.25 & 665.4933 & 1623.918 & 958.4247 \\
\hline Philippines & 3.15 & 4.38 & 1.23 & 1733.693 & 2284.082 & 550.389 \\
\hline Singapore & 3.35 & 4.47 & 1.12 & 6608.918 & 6312.387 & -296.531 \\
\hline Thailand & 3.10 & 3.71 & 0.61 & 1735.088 & 3036.178 & 1301.09 \\
\hline Vietnam & 4.85 & 5.66 & 0.81 & 569.1754 & 1099.078 & 529.9026 \\
\hline
\end{tabular}

Source: World Bank Development Indicators

Further, Figure 1 illustrates the trend in prevailing health spending relative to GDP in Southeast Asian countries from 2000 to 2016. An increasing trend is noticeable in Vietnam, Thailand, Singapore, and the Philippines particularly from 2008 onwards, though at the successive years included in the study the expenditure trend portrays a steady movement. In spite of the cumulative decline in prevailing health expenditure in Brunei, Cambodia, and Laos, there were no significant spikes in the trend of health expenditure in Brunei compared to what is observed in Cambodia and Laos during the sample period.

\section{FIGURE 1: TREND IN PREVAILING HEALTH SPENDING RELATIVE TO GDP IN ASEAN COUNTRIES (2000-2016)}

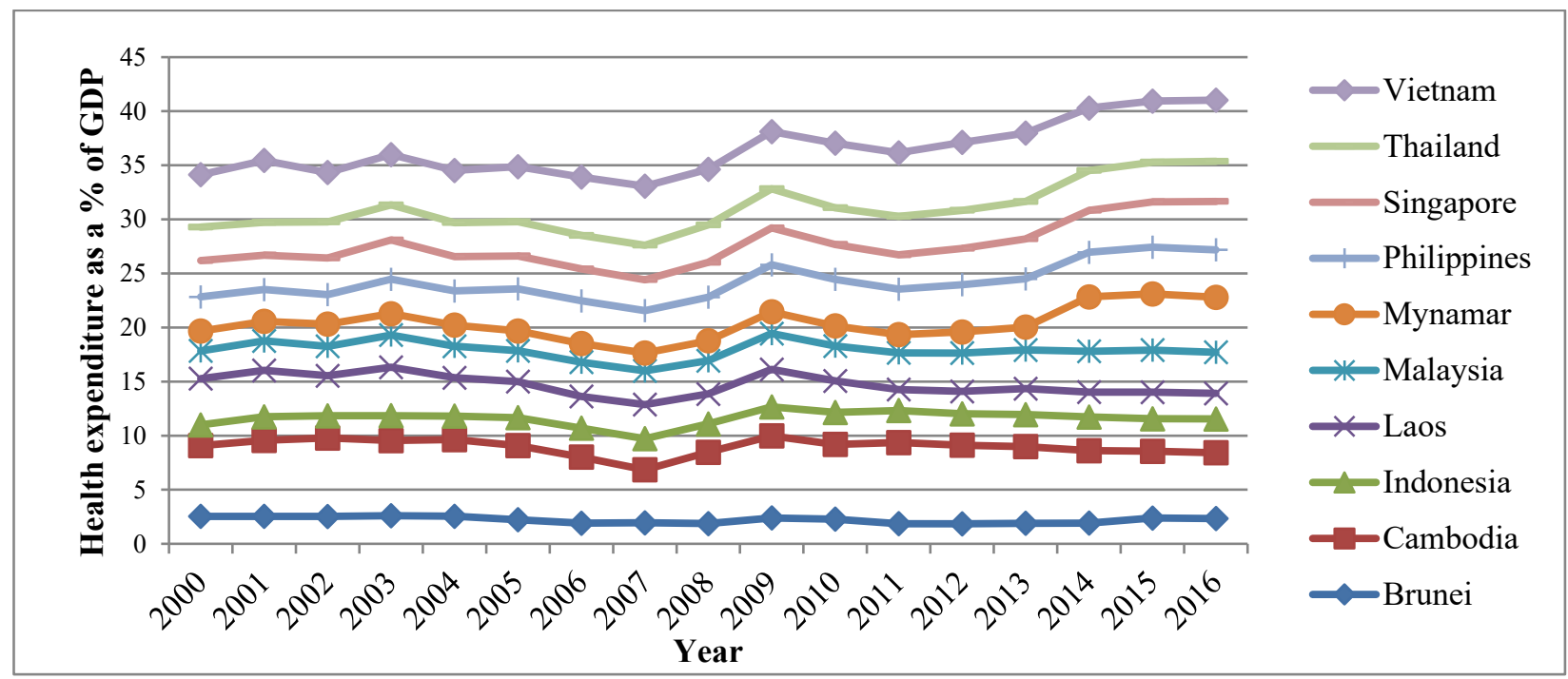


Figure 2 portrays the trend in agricultural productivity growth in terms of value-added per worker at 2010 constant prices in USD for Southeast Asian countries for the 2000 to 2016 study period. Overall, it shows an increasing trend from the beginning of the sample and slightly changed the pattern of growth with more fluctuations after 2004 onwards until it reaches a peak in 2014 and eventually wanes in absolute terms, across the region.

FIGURE 2: TRENDS IN AGRICULTURE, FORESTRY, AND FISHING, VALUE-ADDED PRODUCTIVITY PER WORKER (CONSTANT 2010USD) IN SOUTHEAST ASIAN COUNTRIES (2000-2016)

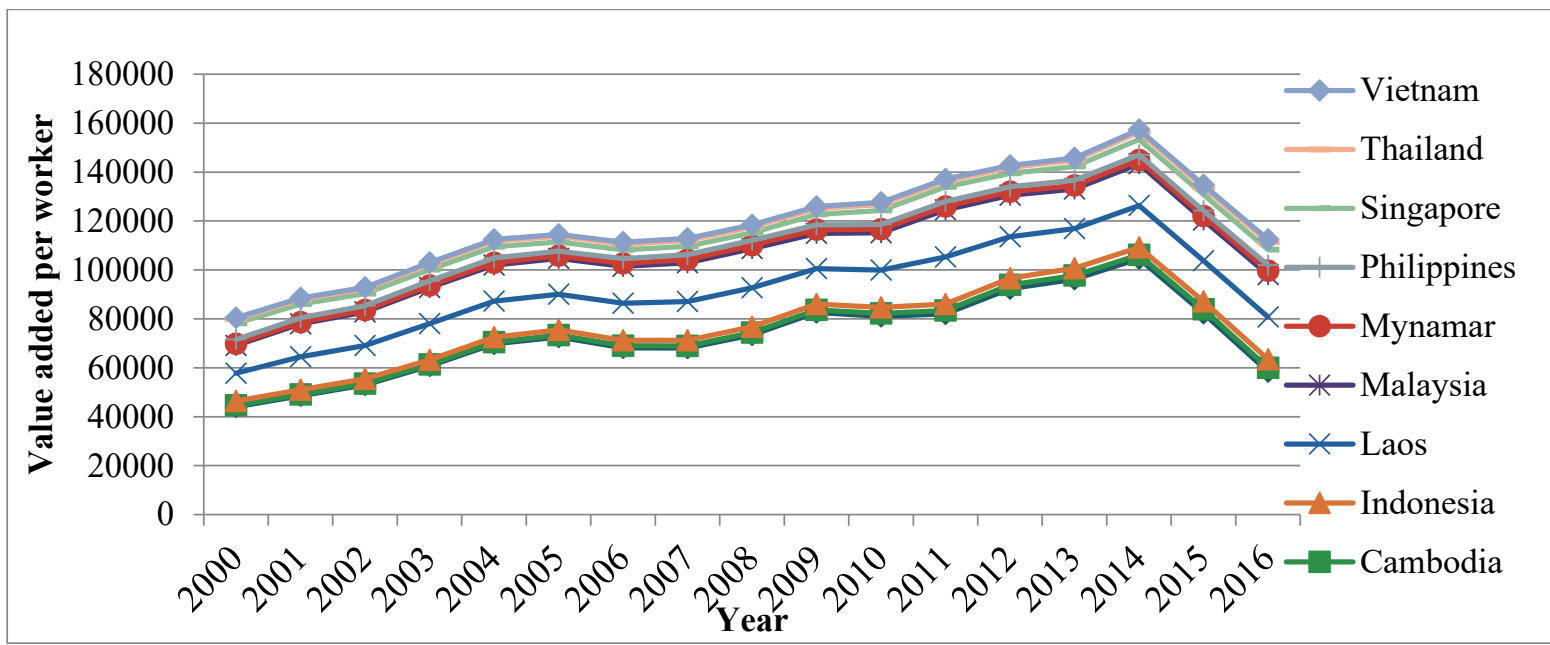

TABLE 2: ESTIMATES OF THE PANEL DATA MODELS

\begin{tabular}{|c|c|c|c|c|c|c|}
\hline \multirow[t]{2}{*}{ PARAMETERS } & \multicolumn{2}{|c|}{$\begin{array}{l}\text { POOLED REGRESSION } \\
\text { MODEL }\end{array}$} & \multicolumn{2}{|c|}{ FIXED EFFECT MODEL } & \multicolumn{2}{|c|}{ RANDOM EFFECT MODEL } \\
\hline & Coefficient & St. Err. & Coefficient & St. Err. & Coefficient & St. Err. \\
\hline InCHE & $-1.476 * * *$ & 0.258 & $0.289 * * *$ & 0.091 & $0.277^{* * *}$ & 0.092 \\
\hline Constant & $9.760^{* * *}$ & 0.329 & $7.611^{* * *}$ & 0.113 & $7.625^{* * *}$ & 0.446 \\
\hline $\mathbf{R}^{2}$ & 0.163 & & 0.059 & & 0.163 & \\
\hline $\mathbf{F}$ & 32.836 & & 9.967 & & --- & \\
\hline Chi-square & ---- & & ---- & & 9.098 & \\
\hline Akaike crit. & 571.364 & & -45.095 & & ----- & \\
\hline Bayesian crit. & 577.636 & & -38.824 & & ----- & \\
\hline Observation & 170 & & 170 & & 170 & \\
\hline Countries & 10 & & 10 & & 10 & \\
\hline Time & 16 & & 16 & & 16 & \\
\hline
\end{tabular}

Three models are considered as candidates for selection based on panel data regression analysis models - the pooled regression, the fixed effect, and the random effect model. Moreover, preliminary diagnostic checks have assisted in identifying the suitable model and the panel data regression estimates are reported in Table 2 . The
Breusch and Pagan Lagrangian multiplier test for random effects is used to select the appropriate model between the random-effects model and ordinary least square regression. Therefore, the LM test null hypothesis is that there is no variance across the Southeast Asian countries. The LM test produced a Chi-square value of 1115.08 and a $p$-value 
of 0.0000 . Thus, this analysis rejects the null hypothesis and concludes that there are significant differences across countries, and hence random effects model is the appropriate model other than the fixed effect and the pooled OLS models. Also, to select the appropriate model between the fixed and the random effect models, this analysis conducts the Hausman specification test. Thus, the Hausman test gives a statistic of -2.11 and a p-value of 0.9540 , and therefore, there is little evidence to dismiss the null hypothesis that the random effect model is the suitable model to be considered for the analysis.

Table 2 depicts the panel data regression estimates consisting of pooled OLS, the fixed effect, and the random effect models. Although the parameters are statistically significant in both the fixed and the random effect models, the LM test statistic favoured the random effect model as the suitable model to obtain unbiased estimators. Further, the analysis performed diagnostic checks to examine the presence of cross-sectional correlation in the chosen model by applying the Pesaran test which gives a statistic of 16.907 and a p-value of 0.6290 , and hence, confirmed that the chosen model does not exhibit contemporaneous correlation in the residuals. However, it was clear that the parameters have the expected signs and are statistically significant in both the fixed and the random effect models. This suggests that prevailing health spending relative to GDP has an elasticity coefficient of 0.28 , suggesting that a unit increase in prevailing health spending relative to GDP would trigger agricultural productivity growth by $28 \%$ across the countries of Southeast Asia, all else constant.

\section{CONCLUSION}

The estimate of the model shows that prevailing health expenditure relative to GDP albeit, statistically significant, has a strong positive elasticity on agricultural productivity growth across the countries of Southeast Asia during the study period. Moreover, this result is consistent with the theoretical argument of the health-led growth hypothesis as put forward by the endogenous growth theory, that health is crucial to economic growth and development. It, therefore, shows that a unit rise in prevailing health spending would substantially stimulate agricultural productivity growth by $28 \%$, across countries of Southeast Asia, ceteris paribus. This result shows that prevailing health spending has comparatively higher elasticity, implying that raising health expenditure directly would greatly increase agricultural productivity growth apart from its indirect effects on boosting per capita income and raising the levels of living across the countries of the region. Therefore, this result clearly supports the notion that augmenting investment in human capital for the promotion of health and economic outcomes simultaneously. This finding is also in agreement with the empirical evidence of previous studies on the study of human capital on productivity growth. It's consistent with the findings of Piabou's comparative panel study between African countries [12] , also in agreement with the study of Arora on ten industrialized economies [14] and that of Aghion's panel study on OECD economies. [16]

Apart from the theoretical consistency of this study's empirical finding, it's pertinent to note that, the result is also vital to monitoring the health target of SGDs across the countries of Southeast Asia. Most countries of Southeast Asia with the exception of Singapore are developing economies with a larger segment of the population employed by the agricultural sector where the vast majority of the unskilled and semi-skilled labourers are actively engaged. Therefore, improving the stock of human capital in the form of sustaining investment in total health spending could improve productivity growth and subsequently better the population's overall living conditions. Notably, the rapid declines in agricultural productivity growth in these countries could be substantially altered by further developing the stock of human capital through improvement in the state of their population health, inter-alia.

However, as agricultural productivity faces rapid declines in ageing populations with a high burden of chronic diseases, more evidence is needed on the right strategy for the governments to scale up their health spending to align with the current SDGs agenda.

However, factors like climate change, natural disasters, and technological advances may have also accounted for the signs of a decline in agricultural productivity per worker. This may serve as the major limitation of the current study. Future studies should consider estimating a more complex model, possibly with the proxy of these variables to give better policy advice. 


\section{AUTHORS' CONTRIBUTIONS:}

SS and MMB conceptualise and designed the proposal of the study; $M M B$ and $\mathrm{HJ}$ collected the data; SS and MMB defined the methodology, analysed, and interpreted the results. MMB drafted the manuscript; SS critically revised the manuscript finally completed the proof-reading. All authors read and approved the final manuscript.

\section{ACKNOWLEDGMENTS:}

We would like to acknowledge the SRM University-AP for providing the database access and research software required for the completion of this study. In addition, a special thanks to Dr. Nishant from Amity University for his critical analysis and proofreading of the research work.

\section{COMPETING INTERESTS:}

The authors declare that they have no known competing financial interests or personal relationships that could have appeared to influence the work reported in this paper.

\section{ETHICAL APPROVAL:}

This study does not require any ethical approval.

\section{References}

1. WHO | Sustainable Development Goal 3: Health. WHO. Accessed January 31, 2021.

http://www.who.int/topics/sustainable-developmentgoals/targets/en/

2. Romer PM. Endogenous technological change. J Polit Econ. 1990;98(5, Part 2): S71-S102.

3. Mother ME, Count C. The World Health Report. WORLD Health. 2005; 11 (5).

4. Mushkin SJ. Health as an Investment. J Polit Econ. 1962;70(5, Part 2):129-157.

5. Liu J, Wang M, Yang L, Rahman S, Sriboonchitta S. Agricultural productivity growth and its determinants in the south and southeast Asian countries. Sustainability. 2020;12(12):4981.

6. Ullah S, Malik MN. Impact of health on labour productivity: empirical evidence from Pakistan. Eur Online J Nat Soc Sci. 2019;8(1):pp-139.

7. Golkhandan A. The Causal Relationship between Health Indicators and Labor Productivity in Iran. Health Res. 2019;4(4):227-234.

8. Wang F. More health expenditure, better economic performance? Empirical evidence from OECD countries. Inq J Health Care Organ Provis Financ. 2015;52:0046958015602666.

9. Raghupathi $\vee$, Raghupathi W. Healthcare expenditure and economic performance: Insights from the United States Data. Front Public Health. 2020;8.

10. Bloom DE, Canning D, Sevilla J. The effect of health on economic growth: a production function approach. World Dev. 2004;32(1):1-13.

11. Ozturk S, Topcu E. Health Expenditures and Economic Growth: Evidence from G8. Published online 2014.

12. Piabuo SM, Tieguhong JC. Health expenditure and economic growth-a review of the literature and an analysis between the economic community for central African States (CEMAC) and selected African countries. Health Econ Rev. 2017;7(1):1-13.

13. Oni LB. Analysis of the growth impact of health expenditure in Nigeria. IOSR J Econ Finance. 2014;3(1):77-84.

14. Arora S. Health, human productivity, and long-term economic growth. J Econ Hist. Published online 2001:699-749.

15. Gyimah-Brempong K, Wilson M. Health human capital and economic growth in Sub-Saharan African and OECD countries. Q Rev Econ Finance. 2004;44(2):296320.

16. Aghion $P$, Howitt $P$, Murtin F. The Relationship between Health and Growth: When Lucas Meets Nelson-Phelps. National Bureau of Economic Research; 2010.

17. Bedir S. Healthcare expenditure and economic growth in developing countries. Adv Econ Bus. 2016;4(2):76-86.

18. Feng W, Xia Y, Kong Y. Public Health Expenditure and Labour Productivity: A Tentative Interpretation Based on the Science of Brain Cognition. NeuroQuantology. 2018;16(5). 